\title{
ENGINEERING MATHEMATICAL MODELLING OF CORONA VIRUS (COVID-19) TRANSMISSION IN IRAQ
}

Emad Kamil Hussein ${ }^{1 *}$, Tayser Sumer Gaaz ${ }^{2}$, Kussay Ahmed Subhi ${ }^{3}$, Samir Ghouali ${ }^{4}$, Mohammed Seghir Guellil

${ }^{1 * 2,3}$ Al-Mussaib Technical College, Al-Furat Al-Awsat Technical University, 51006, Babylon, Iraq; ${ }^{4}$ Faculty of Sciences \& Technology, Mustapha Stambouli University, Mascara, Algeria \& STIC Laboratory, Tlemcen, Algeria; ${ }^{5}$ Faculty of Economics, Business and Management Sciences, MCLDL Laboratory, University of Mascara, 29000, Algeria. Email: *emad_kamil72@atu.edu.iq

Article History: Received on $19^{\text {th }}$ June 2021, Revised on $15^{\text {th }}$ July 2021, Published on $21^{\text {st }}$ July 2021

\begin{abstract}
Purpose: As a result of a sudden spreading of an epidemic novel virus, scientifically named COVID-19, this paper has been done to present a contribution towards fighting this virus in Iraq.
\end{abstract}

Methodology: This investigation is focusing on constructing an engineering mathematical model based on the Suspected, Infected, and Recovered model (SIR), given by Kermack and McKendrick.

Main Findings: Iraqi people are facing and suffering from this COVID-19. Three governorates occupying the locally highest infection levels, plus the world's highest deaths to infected cases ratio of about 11\%, are Baghdad, Sulaimani, and Karbala.

Implications: It is showed that the Reproduction ratio $\left.\mathrm{R}_{0}\right)_{\mathrm{K}}$ is positive (greater than 1 ) in the three nominated zones, which means that the epidemic disease will keep spreading in a broad manner and depending on many specific factors. Many effective recommendations are presented to avoid spreading this novel virus via many techniques.

Novelty: SIR model is used to assess epidemic levels in 3 zones.

Keywords: Corona Virus, COVID-19, Communicable Diseases, Mathematical Modelling, Iraq.

\section{INTRODUCTION}

Since its rise in December 2019, the outbreak of novel Coronavirus Disease 2019 (COVID-19) flare-up has tainted more than 140000 individuals all-inclusive with almost 5400 deaths (Zhao et al., 2000). COVID-19, brought about by the extreme intense respiratory disorder coronavirus 2 (SARS-CoV-2), creates a respiratory and foundational disease that advances to a severe type of pneumonia in 10-15\% of patients (Mission et al. 2020). Extreme COVID-19 can prompt primary ailment, with intense respiratory misery (ARDS) and multi-organ disappointment (MOF) as its essential difficulties, in the long run, followed by intravascular coagulopathy (Mattiuzzi et al. 2020). To streamline quiet consideration and asset distribution during this pandemic, biomarkers are desperately required to stratify patients' hazards and effectively check disease seriousness. Platelet tally is a primary and promptly accessible biomarker, which is freely connected with sickness seriousness and danger of mortality in the emergency unit (Khurana et al. 2017. Vanderschueren et al. 2000, Hui et al. 2011). Besides, low platelet checks associates with higher malady seriousness scores, for example, Multiple Organ Dysfunction Score (MODS), Simplified Acute Physiology Score (SAPS) II, and Acute Physiology and Chronic Health Evaluation (APACHE) II (Vanderschueren et al. 2000).

In the serious, intense respiratory disorder (SARS) flare-up, thrombocytopenia was accounted for to happen in up to $55 \%$

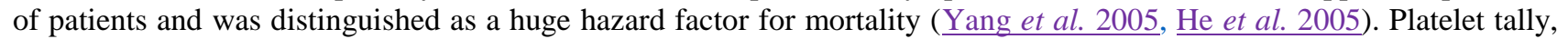
with hypoxemia, were the main two factors utilized by Zou et al. for building up a SARS prognostic model, which showed $96.2 \%$ exactness. Albeit just three months have slipped by since the development of COVID-19, a few investigations and case reports have been as of now distributed in significant universal logical and clinical diaries, from China and different nations with movement and non-travel-related cases (Bastola et al. 2020, Pongpirul et al. 2020, Holshue et al. 2020, Silverstein et al. 2020) Huge numbers of these reports have begun to respond to clinical inquiries, including development and results, just as potential hazard factors, and clinical, research facility and picture discoveries; in any case, a precise audit to merge what has been gained from each examination or revealed case is to-date missing. Albeit efficient surveys and meta-examinations, as a rule, incorporate randomized clinical preliminaries (RCTs) and plan to give a progressively exact gauge of the impact of a treatment or hazard factor for an ailment, likewise have been widely utilized, particularly during the most recent decades, to orchestrated observational investigations (CardonaOspina et al. 2019, Stroup et al. 2000) Much of the time, RCTs are not doable or accessible, and just information from observational investigations are available (Stroup et al. 2000). This is the situation for the clinical, research centre, and picture highlights of COVID-19.

\section{COVID-19 as an Epidemic Phenomenon}

As a result of a complex parameters interference in the society of the Wuhan city in China, a novel virus is created in a strange and rapid manner, that makes this virus has a distinguishing feature, and it is able to reform its abilities and genetic structure based on the ambient of existence and the employed anti-biotics, so that makes this novel virus to be 
rapidly spread not only in the Wuhan city no but in many countries around the world, as indicated in Figure 1(a) and (b) below.

At the same, with the first case of infection, there was no effective medical cure for this novel virus, so that makes the controlling situation is very difficult. The only solution was the immunity system of an infected human body only. There were many cases of the total confirmed, total deaths, and totally recovered cases as indicated in Table 1 below, in addition to the top five highest rates countries until March 12, 2020, 2:47 pm GMT.

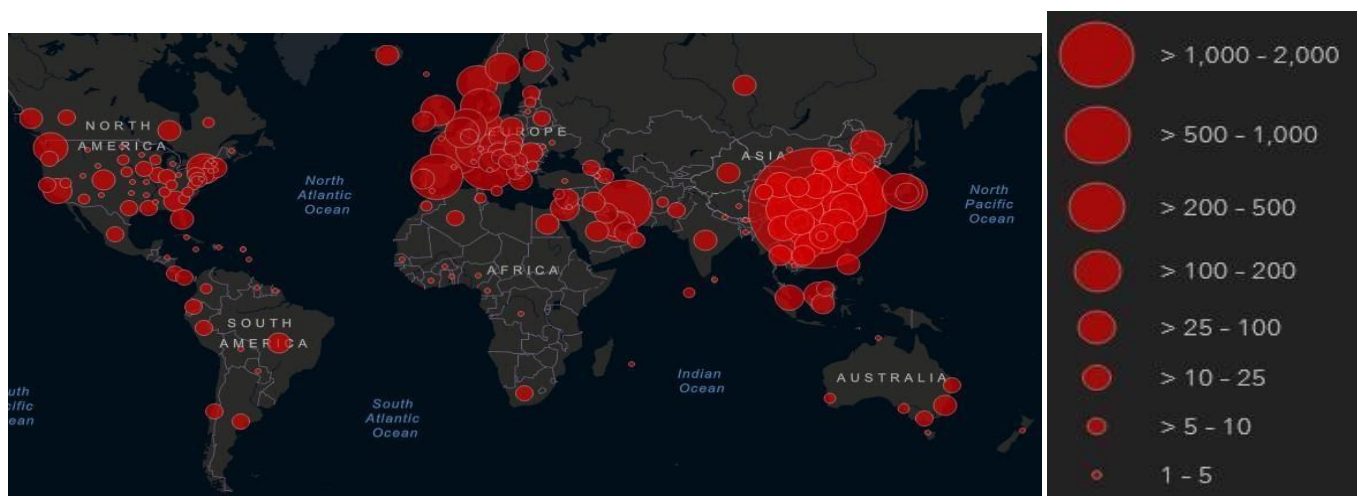

(a)
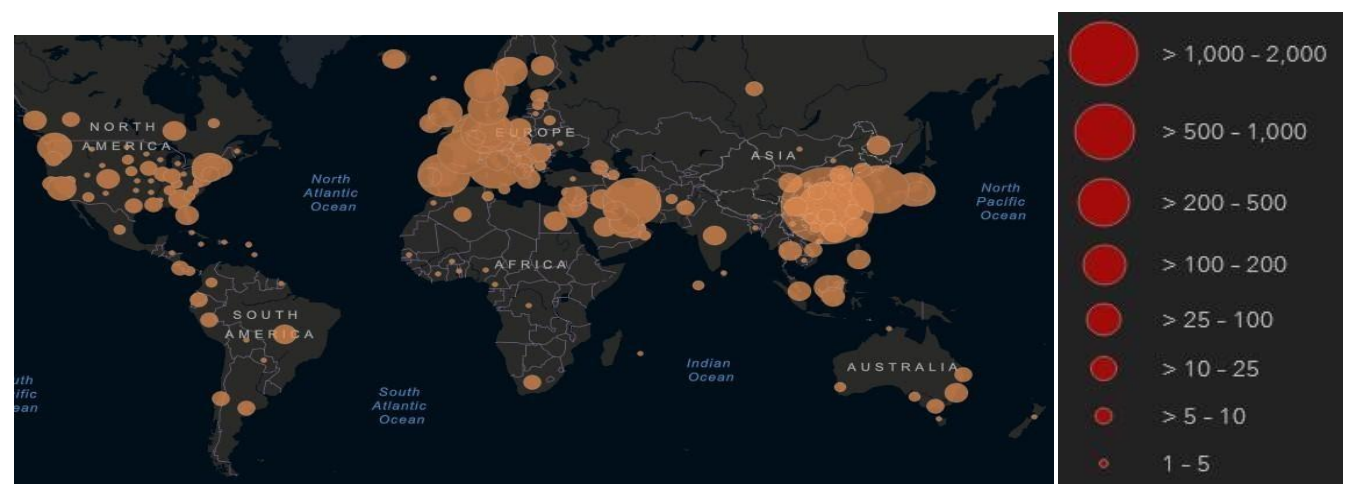

(b)

Figure 1: Corona virus (COVID-19) (a) the total confirmed cases, (b) the total existing cases around the world (Macrotrends et al. 2020)

Table 1: The global Corona virus, COVID-19 total confirmed, deaths, and recovered cases (Macrotrends et al. 2020)

\begin{tabular}{|c|c|c|c|}
\hline \multicolumn{4}{|c|}{ Global Statistics } \\
\hline \multicolumn{2}{|l|}{ Description } & \multicolumn{2}{|c|}{ Number of Cases (person) } \\
\hline \multicolumn{2}{|c|}{ Total Confirmed Cases } & \multicolumn{2}{|l|}{127863} \\
\hline \multicolumn{2}{|c|}{ Total Deaths Cases } & \multicolumn{2}{|l|}{4718} \\
\hline \multicolumn{2}{|c|}{ Total Recovered Cases } & \multicolumn{2}{|l|}{68310} \\
\hline \multicolumn{4}{|c|}{ Top Five Highest Rates Countries } \\
\hline Country & Total Confirmed Cases & Total Deaths Cases & Total Recovered Cases \\
\hline China & 80932 & 3175 & 62892 \\
\hline Italy & 12462 & 827 & 1045 \\
\hline Iran & 10075 & 429 & 2959 \\
\hline Korea, South & 7869 & $66 \mathrm{Pu}$ & 333 \\
\hline France & 2284 & 48 & 12 \\
\hline
\end{tabular}

This paper will concern about the situation on earth for the republic of Iraq, where the first recorded confirmed case was on Monday $24^{\text {th }}$. February 2020, then by direct contact with this foreigner infected man from Iran, many cases have been confirmedly infected, and to get a clear idea about some statistical view about the overall situation in Iraq till the $9^{\text {th }}$. of March 2020, take a look at Table 2 below:

Table 2: The Iraqi Corona virus (COVID-19) total confirmed, deaths, and recovered cases (Mission 2020)

\section{Iraqi Local Statistics \\ Description}

Number of Cases (person) 


\begin{tabular}{llll}
\hline Total Confirmed Cases & 68 & \\
\hline \multicolumn{2}{l}{ Total Deaths Cases } & 7 & \\
\hline \multicolumn{2}{l}{ Total Recovered Cases } & 6 & \\
\hline Iraqi Governorates Local Statistics & & 0 \\
\hline Governorate & Total Confirmed Cases & Total Deaths Cases & Total Recovered Cases \\
\hline Babil & 1 & 1 & 0 \\
\hline Basra & 1 & 1 & 0 \\
\hline Dhi Qar & 1 & 0 & 0 \\
\hline Anbar & 1 & 0 & 0 \\
\hline Muthana & 1 & 0 & 0 \\
\hline Misan & 2 & 1 & 0 \\
\hline Karbala & 3 & 1 & 0 \\
\hline Wasit & 3 & 0 & 0 \\
\hline Diyala & 3 & 0 & 0 \\
\hline Erbil & 3 & 0 & 0 \\
\hline Najaf & 5 & 0 & 4 \\
\hline Kirkuk & 7 & 0 & 0 \\
\hline Sulaimani & 10 & 1 & $\mathbf{2}$ \\
\hline Baghdad & $\mathbf{2 7}$ & $\mathbf{2}$ & \\
\hline
\end{tabular}

Figure 2 below shows in a coloured manner both the suspected and infected cases all over the Republic of Iraq until February 24, 2020.
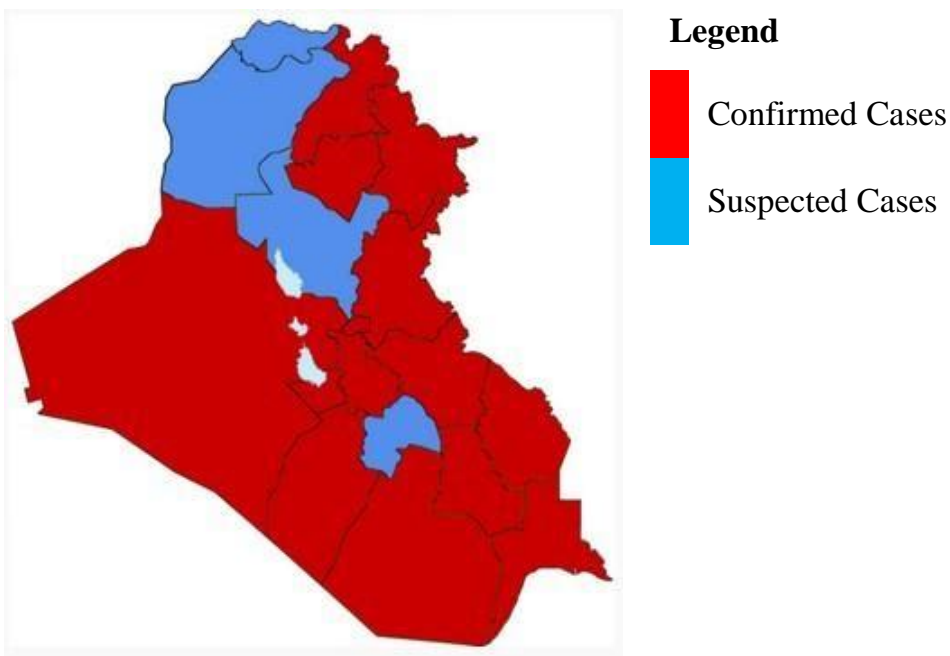

Figure 2: Iraqi confirmed and Suspected with a COVID-19 virus (Shilani et al. 2020)

As indicated in Table 2 above, the governorate of Baghdad is occupying the highest infection level comparing with the other zones within Iraq, so the proposed engineering mathematical model will completely concern the capital Baghdad in analyzing this critical medical situation as in the coming paragraph.

\section{Engineering Mathematical Modelling}

There are many procedures employed to analyze the similar phenomenon of spreading of the novel Corona virus, scientifically named as COVID-19, during the past decades, and in this paper, the Suspected, Infected, and Recovered (SIR) model that has been developed by Kermack and McKendrick will be a theoretical basis of this investigation. Simply, any conservative system must have three main elements, as illustrated in Figure 3 below, and they are some input parameters, $\operatorname{process}(s)$ or operation $(s)$, and infected output parameters.

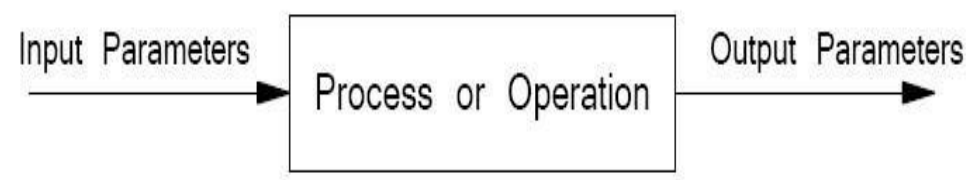

Figure 3: Schematic of a conservative system 
This principle of the conservative system was representing a core idea of the general formula of the SIR model, so Figure 4 below is representing the main schematic of the SIR model with a flow line for indicating the direction of each input, process, and output for all of the action within this proposed conservative system.

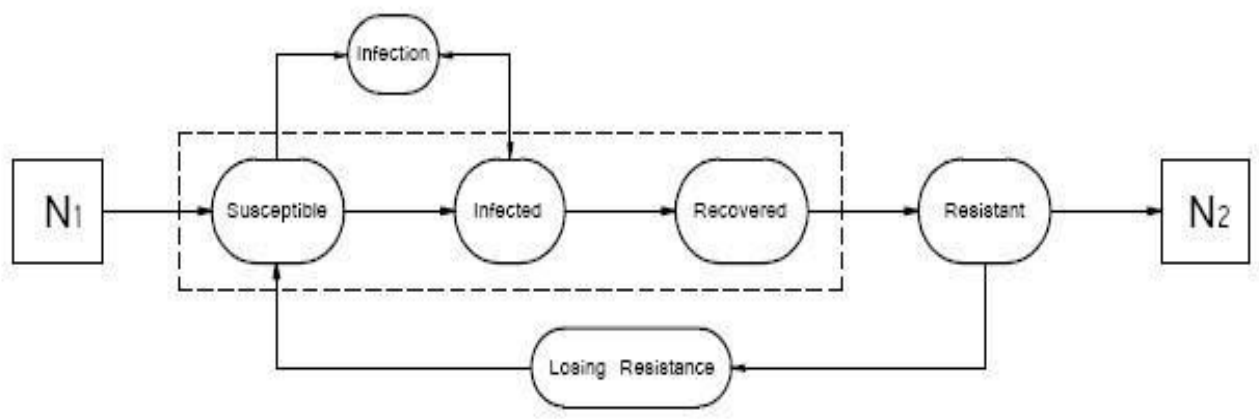

Figure 4: Schematic of a general SIR conservative system

Where $\mathrm{N}_{1}$ and $\mathrm{N}_{2}$ are representing the total population before and after spreading a medical problem, respectively, and the bounded area by a dashed rectangular box is considering as the main factors of SIR analysis. Now the proposed engineering mathematical model will analyze the three main effective factors: Suspected $(S)$, Infected $(I)$, and Recovered $(R)$ as shown in Figure 5 below:

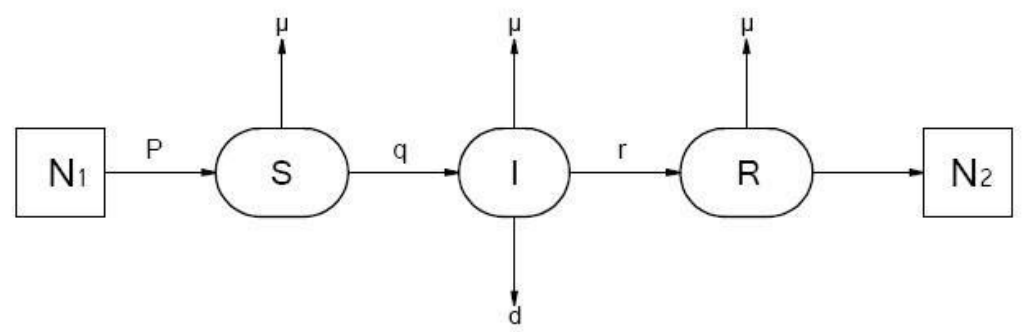

Figure 5: Main three factors of the SIR model

Where $\mu$ is the natural rate of death, $P$ is the input rate of suspected persons, $q$ and $r$ are the infected and recovered cases rates, respectively, and $d$ is the total death rate due to the infection under consideration.

SIR mathematical model may be represented by a set of first-order, first-degree ordinary differential equations as in the coming lines: Figure 6 shows the proposed model for the Suspected cases $(S)$ icon:

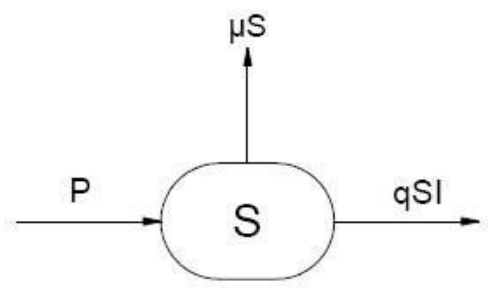

Figure 6: The $S$ icon in the SIR model

hence, $\frac{d S}{d t}=P-q S I-\mu S$

and the followed icon for the Infected cases $(I)$ is illustrated in Figure 7:

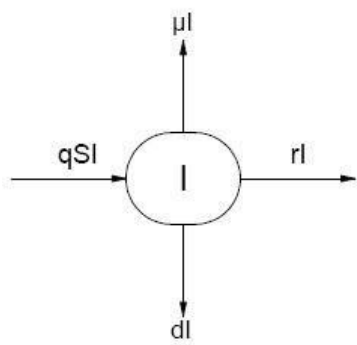

Figure 7: The $I$ icon in the SIR model 
Based on the $I$ icon, the infected cases equation could be written as in Eq. (2a), and Eq. (2b)

$$
\frac{d I}{d t}=q S I-r I-\mu I-d I
$$

or $\frac{d I}{d t}=q S I-(r+\mu+d) I$

With the same technique, the Recovered cases formulation with being as indicated in Figure 8:

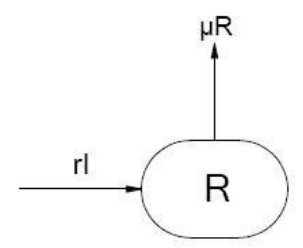

Figure 8: The $R$ icon in the SIR model

$$
\frac{d R}{d t}=r I-\mu R
$$

but $S+I+R=1$, hence $\frac{d S}{d t}=\frac{d I}{d t}=\frac{d R}{d t}=0$,

where the SIR epidemic model is in equilibrium, yields:

$$
\begin{aligned}
& \frac{d S}{d t}=P-q S I-\mu S=0 \\
& \frac{d I}{d t}=q S I-(r+\mu+d) I=0 \\
& \frac{d R}{d t}=r I-\mu R=0
\end{aligned}
$$

and according to the logic interaction between the four rates around the $I$ icon, see Figure 9, it yields:

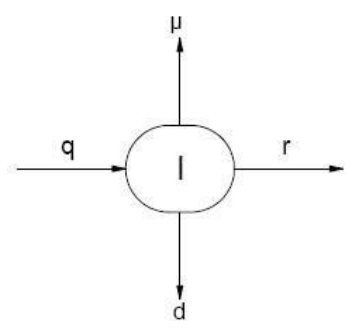

Figure 9: The mutual interaction of the four rates around the $I$ icon

The principal reproduction value $R_{0}$, where $R_{0}$ is representing a reproduction rate value and may be defined as the average gained the total number of secondarily infected peoples generated by one primary infected case within the total number of a suspected population and will equal to:

$$
R_{0}=\frac{q}{(r+d+\mu)}
$$

The most important icon in the SIR epidemic model is the $I$ because it represents a critical three intersected results, either natural death, total recovery, or death due to the COVID-19 virus infection, so it is essential to deeply analysis this central $I$ icon as follows: 
$\frac{d I}{d t}=\frac{q}{(r+d+\mu)}(r+d+\mu) S I-(r+\mu+d) I$

$\frac{d I}{d t}=R_{0}(r+d+\mu) S I-(r+\mu+d) I$

$\frac{d I}{d t}=I(r+d+\mu)\left[R_{0} S-1\right]$

As a result of the continuous spreading of this novel COVID-19 virus during the time duration of preparing this investigation, the reproduction value must be positive always, $R_{0}>0$, so the infection variation with respect to time must also be positive, $\frac{d I}{d t}>0$, so in return to Eq. (5), yields:

$$
\begin{aligned}
& \frac{d I}{d t}=q S I-(r+\mu+d) I=0 \\
& {[q S-(r+d+\mu)] I=0}
\end{aligned}
$$

Either $I=0$, but it is no meaning, where this means no infected cases! And leads to $R=0$, which is also meaning no generation of newly infected cases, then $I \neq 0$,

or $[q S-(r+d+\mu)]=0$

or $S=\frac{(r+d+\mu)}{q}$

now substitute Eq. (11) into Eq. (4), gives:

$$
\begin{aligned}
& P-q\left[\frac{(r+d+\mu)}{q}\right] I-\mu\left[\frac{(r+d+\mu)}{q}\right]=0 \\
& P-(r+d+\mu) I-\mu\left[\frac{(r+d+\mu)}{q}\right]=0 \quad(r+d+\mu) I=P-\mu\left[\frac{(r+d+\mu)}{q}\right] \\
& I=\frac{q P-\mu(r+d+\mu)}{q(r+d+\mu)}
\end{aligned}
$$

by substituting Eq. (12) into Eq. (6), produces:

$$
\begin{gathered}
r\left[\frac{q P-\mu(r+d+\mu)}{q(r+d+\mu)}\right]-\mu R=0 \\
\text { or } R=r\left[\frac{q P-\mu(r+d+\mu)}{q \mu(r+d+\mu)}\right] \ldots
\end{gathered}
$$

so to reform Eq. $(11,12$, and 13$)$, it is better to use matrix notation as follows:

$$
E=[S, I, R]=\left[\begin{array}{lll}
\frac{P}{\mu} & 0 & 0
\end{array}\right]
$$


$E=\left[\left(\frac{(r+d+\mu)}{q}\right),\left(\frac{q P-\mu(r+d+\mu)}{q(r+d+\mu)}\right),\left(r\left(\frac{q P-\mu(r+d+\mu)}{q \mu(r+d+\mu)}\right)\right)\right]$

So, Table 3 below summarizes this set of essential equations as follows:

Table 3: Summary of a set of essential SIR epidemic equations model

\begin{tabular}{llll}
\hline$E$ & $S$ & $I$ & $R$ \\
\hline$E$ & $\left(\frac{(r+d+\mu)}{q}\right)$ & $\left(\frac{q P-\mu(r+d+\mu)}{q(r+d+\mu)}\right)$ & $\left(r\left(\frac{q P-\mu(r+d+\mu)}{q \mu(r+d+\mu)}\right)\right)$ \\
\hline
\end{tabular}

Based on Eqs. $(4,5$, and 6), and to examine the regional stability of the epidemic COVID-19 virus-free equilibrium state

$(E)$, it is essential to construct the Jacobian matrix in association with the major assumption of $E=\left[\begin{array}{lll}\frac{P}{\mu} & 0 & 0\end{array}\right]_{\text {as }}$ indicated in the following matrix:

$J(E)=\left[\begin{array}{ccc}-q I-\mu & -q S & 0 \\ q I & q S-(r+d+\mu) & 0 \\ 0 & r & -\mu\end{array}\right]$

and by adding the Eigenvalues $(\varphi)$ to the Jacobian matrix, yields: $[J(E)-\varphi]$, or

$[J(E)-\varphi]=\left[\begin{array}{ccc}-q I-\mu-\varphi & -q S & 0 \\ q I & q S-(r+d+\mu)-\varphi & 0 \\ 0 & r & -\mu-\varphi\end{array}\right]$

where $\varphi$ are the Eigen values of Jacobian and having the following values:

$-q I-\mu-\varphi_{1}=0$, so

$\varphi_{1}=-q I-\mu$

$q S-(r+d+\mu)-\varphi_{2}=0$, so

$\varphi_{2}=q S-(r+d+\mu)$

$-\mu-\varphi_{3}=0$

$\varphi_{3}=-\mu$

Now the next step is to find the determine of the Jacobian matrix, which must equal to zero as follows:

$$
\begin{aligned}
& |J(E)-\varphi|=(-q I-\mu-\varphi)\left|\begin{array}{cc}
q S-(r+d+\mu)-\varphi & 0 \\
r & -\mu-\varphi
\end{array}\right|=0 \quad, \text { or } \\
& |J(E)-\varphi|=(-q I-\mu-\varphi)\{(q S-(r+d+\mu)-\varphi)(-\mu-\varphi)\}=0 \\
& (-q I-\mu-\varphi)\{(q S-(r+d+\mu)-\varphi)(-\mu-\varphi)\}=0
\end{aligned}
$$

so, since the novel COVID-19 virus is still spreading rapidly in many countries without the presence of any effective vaccine around the globe, it is impossible to say that the novel communicable disease-free equilibrium is stable! 
Furthermore, in order to say that the disease-free equilibrium is stable as the ratio $\left(\frac{q P}{\mu}\right)$ must be less than the summation of $(r+d+\mu)$, where $\left(\frac{q P}{\mu}\right)$ is the total infected cases within the total population.

\section{Numerical Application}

Table 4 gives a clear idea about the total situation in some of the Iraqi governments, so to conduct a numerical application and statistics based on the above SIR epidemic mathematical model, three governorates with the highest rates of infection has been nominated are: Baghdad, Sulaimani, and Karbala, in addition, Iraq is occupying the highest infection to death ratio around the world (Shilani. H, 2020), where this ratio is equal to $11.2 \%$ followed by Italy $6.6 \%$ and Iran $3.9 \%$.

Table 4: The Iraqi Corona virus (COVID-19) total confirmed, deaths, and recovered cases (Shilani et al. 2020)

\begin{tabular}{llll}
\hline Iraqi Governorates Local Statistics & & \\
\hline Governorate & Total Confirmed Cases & Total Deaths Cases & Total Recovered Cases \\
\hline Baghdad & $\mathbf{2 7}$ & $\mathbf{2}$ & $\mathbf{2}$ \\
\hline Sulaimani & 10 & 1 & 0 \\
\hline Karbala & 3 & 1 & 0 \\
\hline
\end{tabular}

Furthermore, Table 5 illustrates to total population in the above mentioned three governorates:

Table 5: Baghdad, Sulaimani, and Karbala Populations (Macrotrends et al. 2015)

\begin{tabular}{ll}
\hline \multicolumn{2}{l}{ Iraqi Governorates Local Statistics } \\
\hline Governorate & Total Populations (persons) \\
\hline Baghdad & 7144000 \\
\hline Sulaimani & 739000 \\
\hline Karbala & 555000 \\
\hline
\end{tabular}

Figure 10 (a, b, and c) are giving the populations in 2020 for the three Iraqi governorates under investigation, Baghdad, Sulaimani, and Karbala, with the extrapolation for the coming two years (Macrotrends et al. 2015):

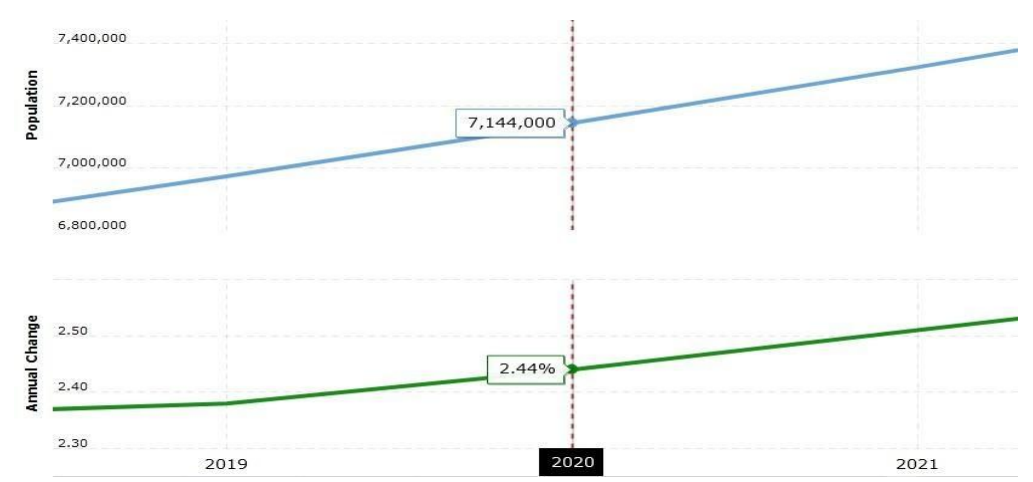

Figure 10 (a): Baghdad Governorate Population 2020 (Macrotrends et al. 2015)

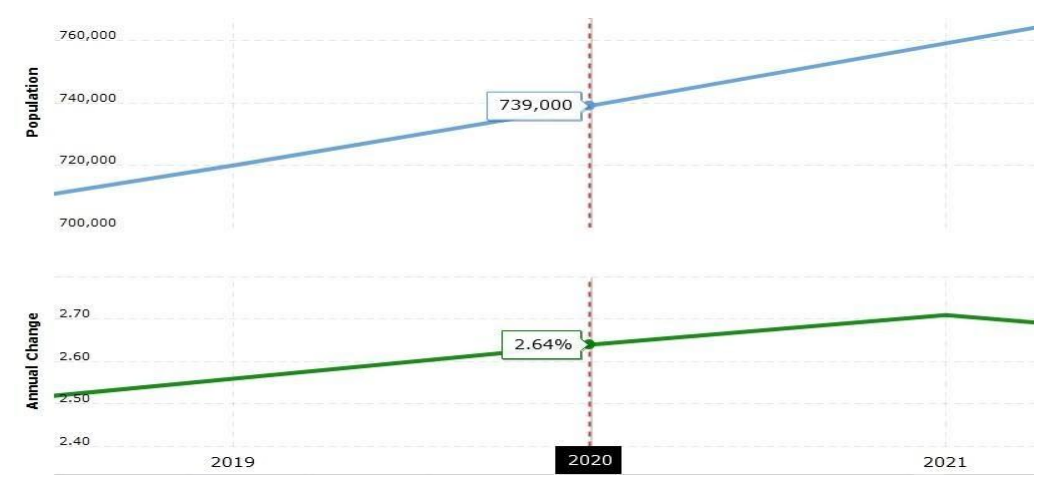

Figure 10 (b): Sulaimani Governorate Population 2020 (Macrotrends et al. 2015) 


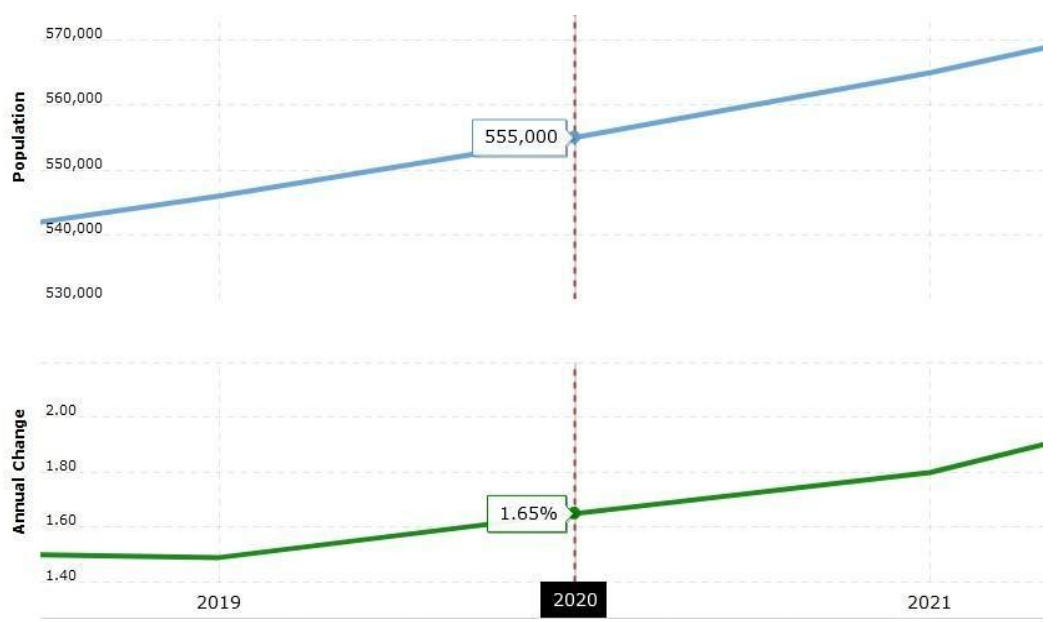

Figure 10 (c): Sulaimani Governorate Population 2020 (Macrotrends et al. 2015)

Now in return to Eq. (9) $\frac{d I}{d t}=I(r+d+\mu)\left[R_{0} S-1\right]$

$I(r+d+\mu)$ is impossible to be equal to zero, i.e if it is equal to infected cases, but actually, the situation on earth is a presence of tens of the infected cases at the above-mentioned governorates with variant infections levels; therefore, the second term $\left[R_{0} S-1\right]$ must be equal zero, hence:

$\left[R_{0} S-1\right]=0$

$R_{0} S=1$

$R_{0}=\left(\frac{1}{S}\right)$

$R_{0}=\left(\frac{K}{\text { or }}\right)$

where $\mathrm{K}$ is an arbitrary numerical constant, and for conducting the required calculations for finding the expected Reproduction ratios, $\left.\mathrm{R}_{0}\right)_{\mathrm{K}}$, let $K=\left[\begin{array}{lllll}0.2 & 0.4 & 0.6 & 0.8 & 1.0\end{array}\right]$, then:

Regarding the Baghdad situation:

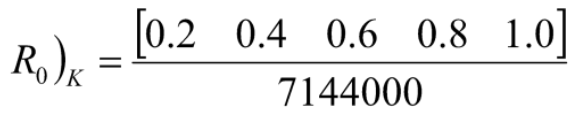

so, table (6) gives the gained Reproduction ratios $\left.\mathrm{R}_{0}\right)_{\mathrm{K}}$ :

Table 6: Baghdad Reproduction ratios

Regarding Sulaimani situation:

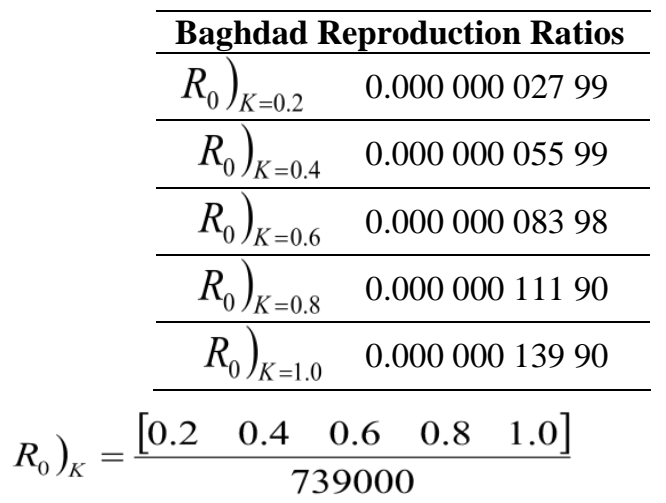

Table 7 summarizes the obtained values of the Reproduction ratios $\left.R_{0}\right)_{K}$ : 
Table 7: Sulaimani Reproduction ratios

Regarding Karbala situation:

\begin{tabular}{cc}
\hline \multicolumn{2}{c}{ Sulaimani Reproduction Ratios } \\
\hline$\left.R_{0}\right)_{K=0.2}$ & 0.00000027 \\
\hline$\left.R_{0}\right)_{K=0.4}$ & 0.00000054 \\
\hline$\left.R_{0}\right)_{K=0.6}$ & 0.00000081 \\
\hline$\left.R_{0}\right)_{K=0.8}$ & 0.00000108 \\
\hline$\left.R_{0}\right)_{K=1.0}$ & 0.00000135 \\
\hline
\end{tabular}

$$
\left.R_{0}\right)_{K}=\frac{\left[\begin{array}{lllll}
0.2 & 0.4 & 0.6 & 0.8 & 1.0
\end{array}\right]}{555000}
$$

Table 8 summarizes the obtained values of the Reproduction ratios $\left.R_{0}\right)_{K}$ :

Table 8: Karbala Reproduction ratios

\begin{tabular}{cc}
\hline \multicolumn{2}{c}{ Karbala Reproduction Ratios } \\
\hline$\left.R_{0}\right)_{K=0.2}$ & 0.00000036 \\
\hline$\left.R_{0}\right)_{K=0.4}$ & 0.00000072 \\
\hline$\left.R_{0}\right)_{K=0.6}$ & 0.00000108 \\
\hline$\left.R_{0}\right)_{K=0.8}$ & 0.00000144 \\
\hline$\left.R_{0}\right)_{K=1.0}$ & 0.00000180 \\
\hline
\end{tabular}

The statistical treatment of the above-tabulated data for the Reproduction ratios as a function of the recently updated populations for the three nominated governorates is indicated in Figure 11(a, b, c, d, and e), where the x-axis represents the selected three governorates and the y-axis is representing the associated values of the Reproduction ratios, taking into account variation of the arbitrary constant $\mathrm{K}$.

Figure 11(a) gives a clear idea about the highest value of $\left.\mathrm{R}_{0}\right)_{\mathrm{K}}$ comparing with the other two infected zones, followed by Sulaimani; meanwhile, Baghdad has the lowest value.

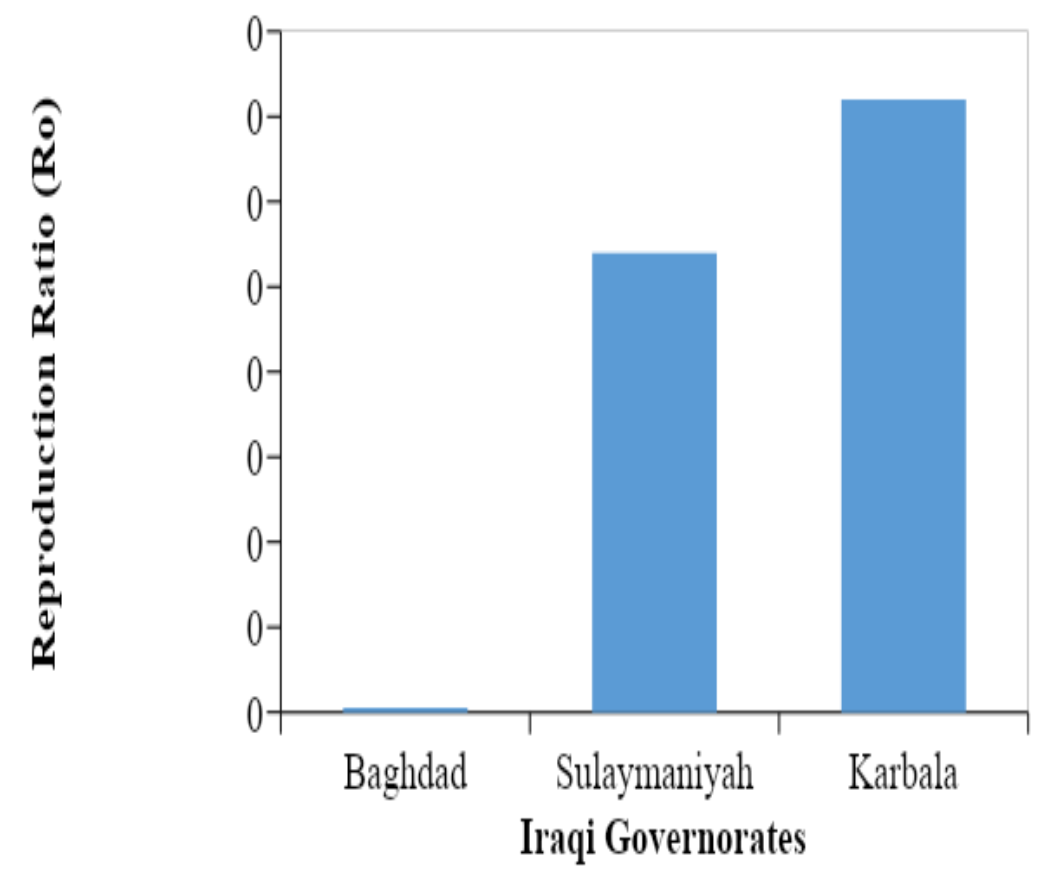

Figure 11(a): Reproduction ratio as a function of the governorate, $\mathrm{K}=0.2$ 
After few days, the infection situation is starting to vary according to the increase of the infected cases, as shown in Figure 11 (b) below:

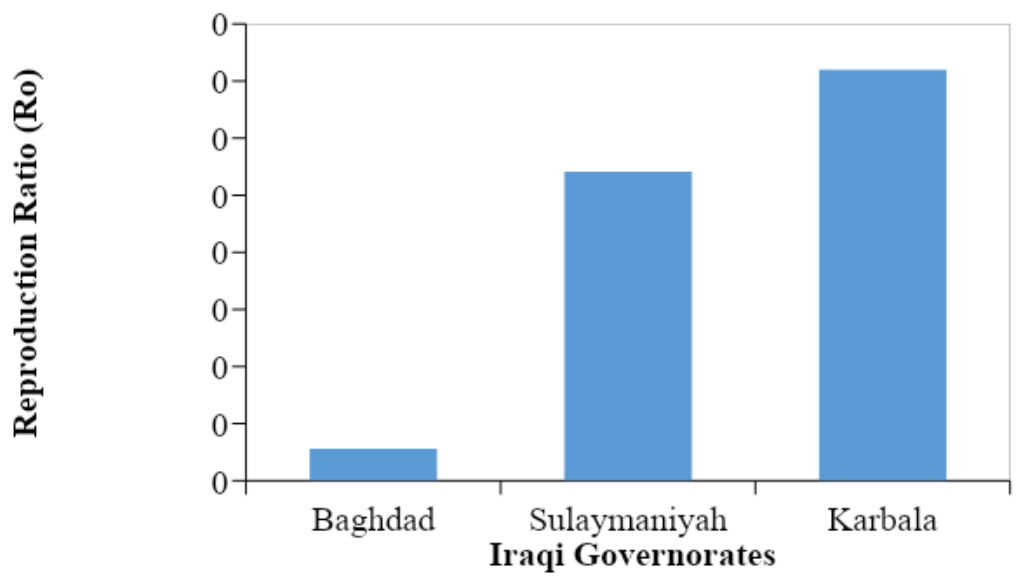

Figure 11(b): Reproduction ratio as a function of the governorate, $\mathrm{K}=0.4$

Again, due to increment of the active and infected cases, which is highly affected by the increment of the suspected cases, the acquired values $\left.R_{0}\right)_{K}$ are also changing as shown in Figure 11(c) below:

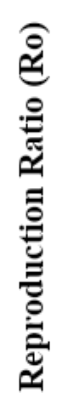

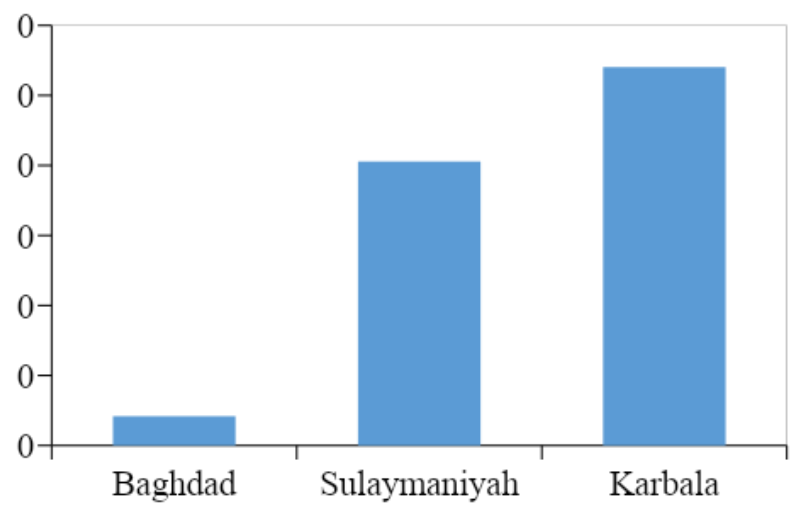

Iraqi Governorates

Figure 11(c): Reproduction ratio as a function of the governorate, $\mathrm{K}=0.6$

This comparison in each one of the graphical sketches must be based on the same value of the arbitrary constant $\mathrm{K}$ to conduct comparing process between the three governorates at the same value of $\mathrm{K}$ in each sketch, Figure 11(d) is approximately giving the same values as in Figure 11(c), but Karbala is still occupying the highest level, then Sulaimani, followed by Baghdad.

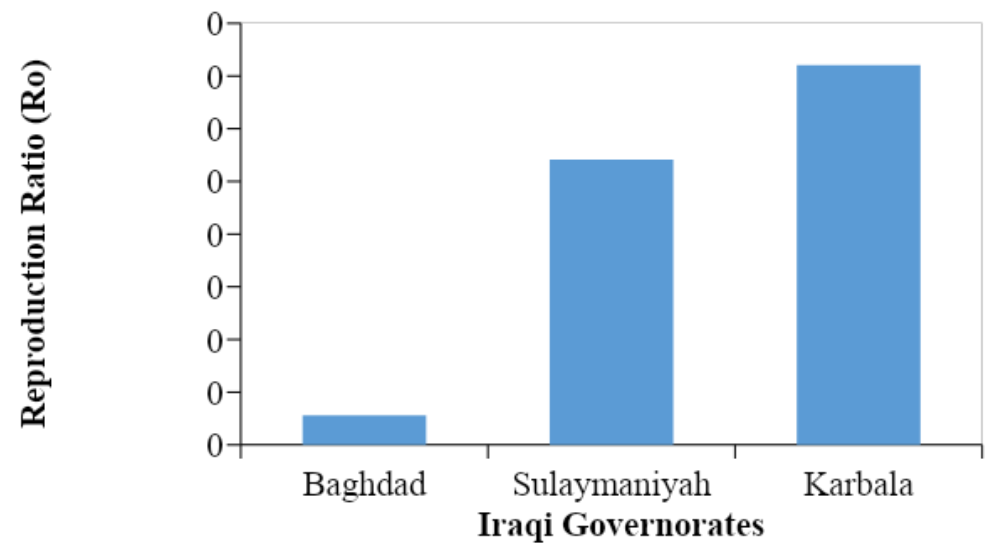

Figure 11(d): Reproduction ratio as a function of the governorate, $\mathrm{K}=0.8$

Figure 11(e) below illustrates a constancy of the Reproduction ratio with three selected zones with a peak value of the arbitrary constant $K$, which is an equal one, and Karbala is still at the top-ranking comparing with the other two zones. It is important to mention that the total population $\mathrm{N}$ of Karbala is lee than the other two cities, but the total number of the suspected cases and then the primary infected cases are relatively times higher than the remaining cities; this is 
confirming the positivity of the Reproduction ratio (it is a good idea to return to the scientific definition of the $\left.\mathrm{R}_{0}\right)_{\mathrm{K}}$ ), and this will be deeply explained in the coming paragraphs.

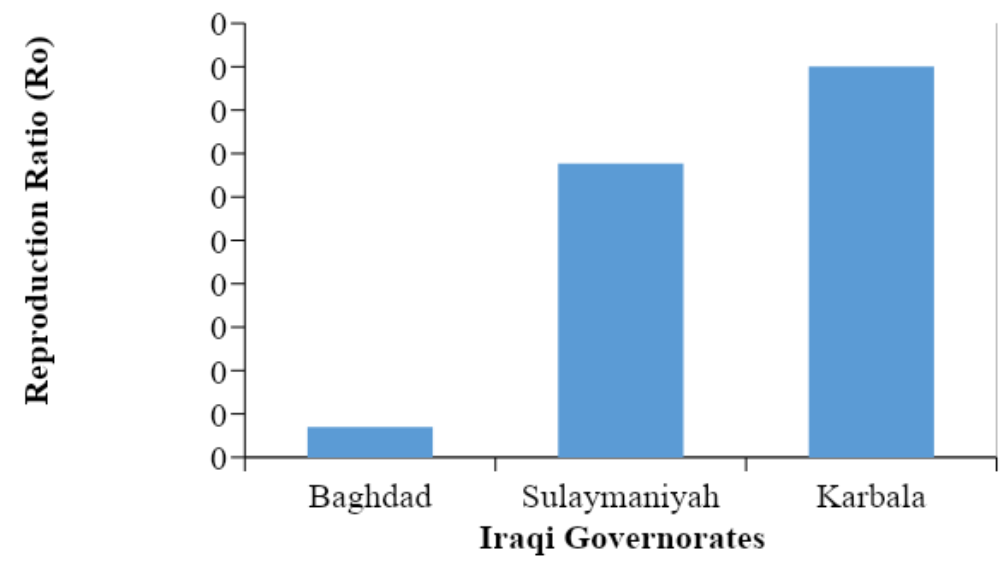

Figure 11(e): Reproduction ratio as a function of the governorate, $\mathrm{K}=1.0$

Figure 12 below gives an updated situation in the three scheduled Iraqi governorates from February 24 up to March 14, 2020, where the black, green, and yellow lines are representing the total number of deaths due to the COVID-19 virus recovered and infected cases, respectively. As per this trusted data, Iraq is at the international highest top-ranking level of the ratio of deaths to infected cases, with about $11 \%$, so that stimulates us to conduct this investigation to at least present a contribution in this regards to safe humanity from this epidemic disease.

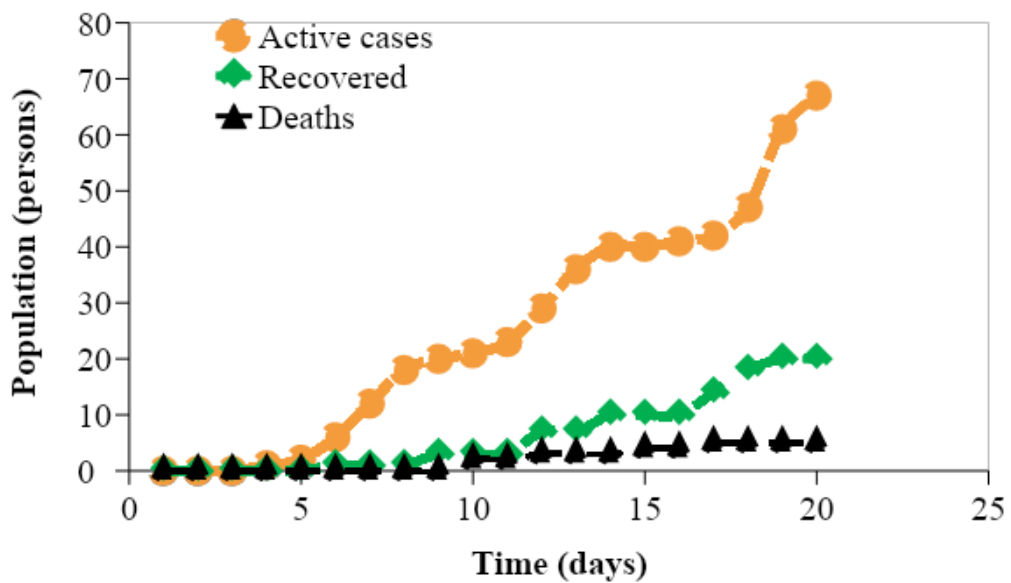

Figure 12: Active, Recovered, and Deaths in Baghdad, Sulaimani, and Karbala from the February 24 up to March 14, 2020 (Shilani et al. 2020)

\section{RESULTS AND DISCUSSION}

According to the achieved analyzed results, the Reproduction function values have positive values, i.e. $\left.R_{0}\right)_{K}>0$, so that supports the overall situation in the three investigated governorates and positively comply with the following achieved points:

1. Total suspected cases are in a continuous increase and consequently, cause an increment in the positively tested (infected) cases population as the days go on.

2. Since $\left.R_{0}\right)_{K}>0$ is positive, so that means the COVID-19 virus disease-free equilibrium (E) is unstable; in other words, the proposed mathematical model predicts that this novel virus will keep spreading in a wide range manner, especially that till this moment there is NO effective vaccine or medications to be taken in the infected people!

3. The proposed hypothesis is verified with an accepted level in matching with the critical spreading situation.

\section{CONCLUSIONS}

Based on the above conducted mathematical model and the collected data from different resources within the three Iraqi governorates, the following remarks may be concluded:

1. The COVID-19 will keep spreading along with the three governorates besides the other zones, so we as a researcher have been added recommendations to stop this novel virus. 
2. Spreading of the COVID-19 is having fluctuated rational values in the governorates under investigation, and this is effectively due to many factors, like, the total number of populations, ambient temperature, level of responsibility, and education level in between communities individuals.

3. Despite no effective vaccine or medication, there are many totally recovered cases so that consolidate the positive natural reaction of a human body via his immune system.

\section{RECOMMENDATIONS}

There is no doubt that the world in general, and the Iraqi people in particular, are facing and suffering from a novel epidemic disease named COVID-19, and till the date of preparing this investigation, there is no effective vaccine or medication to treat this virus! Hence, we as a researcher are presenting the following important recommendations:

1. "Stay at home, stay clean, stay safe", since human-to-human transmissions have been confirmed with incubation time duration of about 2 up to 14 days.

2. All the individuals must take an effective mutually cooperative step(s) towards preventive themselves from suspected cases to avoid the virus spreading.

3. Scientifically and experimentally, the excellent sanitizer is the $0.1 \%$ Sodium Hypochlorite ( $\mathrm{NaOCl}$ ) fluid, hence using this easily prepared solution is extremely necessary to decontaminate all surfaces in home, office, and other daily contacting zones, plus washing hands with a clean water and soap for not less than 30 seconds many times per daylight.

4. Try to consolidate your immune system by consuming a recommended daily dose of fresh vitamin $\mathrm{C}$ and fresh, clean fruit, and healthy food.

5. Sport is giving happiness and rebuilding your body to be a resistible system against disease, including viral attacks.

6. Keep calm, moderate, optimistic, and positive with your family members.

In addition, with smartphone applications, patients can connect with doctors via video conferencing and enjoy a virtual tour that looks very much like an examination room. With the spread of COVID-19, a time-saving innovation can now literally save lives. But to take advantage of this opportunity, we must recognize the importance of telemedicine and take steps to implement it immediately. The benefits of telemedicine lie in three key areas: prevention of transmission, provision of remote care, and increasing the human resources available in the health sector. The most obvious benefit of telemedicine in an epidemic is that patients and health care providers can meet each other without the risk of transmitting infection. The ways in which telemedicine increases our supply of healthcare professionals are subtler but also of paramount importance.

\section{ACKNOWLEDGEMENT}

The present work was undertaken under the support and fund of the Al-Furat Al-Awsat Technical University (ATU), Iraq, and the Faculty of Sciences and Technology, Mustapha Stambouli University Mascara, Algeria \& STIC Laboratory, Tlemcen, Algeria. Also, many thanks to the World Health Organization, WHO, and the Iraqi Ministry of Health for their kind providing us with trusted and recorded updated data. The author acknowledges the constant support encouragement of Professor Dr. Eng. Andrei Tudor, Politehinca University of Bucharest, Romania, and Prof. Dr. Adel Obaid Hssoni, Biological Control Department, Al-Mussaib Technical College, Al-Furat Al-Awsat Technical University, Babil, Iraq, for his scientifically tough support and comments.

\section{REFERENCES}

1. Bastola, A., Sah, R., Rodriguez-Morales, A. J., Lal, B. K., Jha, R., Ojha, H. C., et al.(2020). The first 2019 novel coronavirus case in Nepal. The Lancet Infectious Diseases, 20, 279-280. https://doi.org/10.1016/S14733099(20)30067-0

2. Cardona-Ospina, J. A., Henao-SanMartin, V., Acevedo-Mendoza, W. F., Nasner-Posso, K. M., MartínezPulgarín, D. F., Restrepo-López, A., et al. (2019). Fatal Zika virus infection in the Americas: A systematic review. International Journal of Infectious Diseases, 88, 49-59. https://doi.org/10.1016/j.ijid.2019.08.033

3. He, W., Chen, S., Liu, X., Li, Y., Xiao, Z. and Zhong, N. (2003). Death risk factors of severe acute respiratory syndrome with acute respiratory distress syndrome. Zhongguo Wei Zhong bing Ji jiu Yi xue= Chinese critical care medicine $=$ Zhongguo weizhongbing jijiuyixue, 15, 336-337.

4. Holshue, M. L., DeBolt, C., Lindquist, S., Lofy, K. H., Wiesman, J., Bruce, H. et al. (2020). First case of 2019 novel coronavirus in the United States. New England Journal of Medicine, 382, 929-936 https://doi.org/10.1056/NEJMoa2001191

5. Hui, P. Cook, D. J., Lim, W., Fraser, G. A., and Arnold, D. M.(2011). The frequency and clinical significance of thrombocytopenia complicating critical illness: a systematic review. Chest, 139, 271-278. https://doi.org/10.1 378/chest.10-2243 
6. Khurana, D. and Deoke, S. A.(2017). Thrombocytopenia in critically ill patients: Clinical and laboratorial behaviour and its correlation with short-term outcome during hospitalization. Indian journal of critical care medicine: peer-reviewed, official publication of Indian Society of Critical Care Medicine, 21, 861-864. https://doi.org/10.4103/ijccm.IJCCM_279_17

7. Macrotrends (2000). https://www.macrotrends.net/cities/21529/baghdad/population.

8. Mattiuzzi, C. and Lippi, G. (2020). Which lessons shall we learn from the 2019 novel coronavirus outbreak. Annals of Translational Medicine, 8(3), 48. https://doi.org/10.21037/atm.2020.02.06

9. Mission, W. (2020). Report of the who-china joint mission on coronavirus disease 2019 (covid-19). WHO, 2020.

10. Pongpirul, W. A., Pongpirul, K., Ratnarathon, A. C., and Prasithsirikul, W. (2020). Journey of a Thai taxi driver and novel coronavirus. New England Journal of Medicine, 382, 1067-1068. https://doi.org/10.10 $\underline{\text { 56/NEJMc2001621 }}$

11. Shilani, H. (2000). World Health Organization. COVID-19 Outbreak Cases in Iraq.

12. Silverstein, W. K., Stroud, L., Cleghorn, G. E. and Leis, J. A. (2020). First imported case of 2019 novel coronavirus in Canada, presenting as mild pneumonia. The Lancet, 395(10225), 734. https://doi.org/10.101 6/S0140-6736(20)30370-6

13. Stroup, D. F., Berlin, J. A., Morton, S. C., Olkin, I., Williamson, G. D., Rennie, D., et al. (2000). Meta-analysis of observational studies in epidemiology: a proposal for reporting. Jama, 283, 2008-2012. https://doi.org/10 $.1001 /$ jama.283.15.2008

14. Vanderschueren, S., De Weerdt, A., Malbrain, M., Vankersschaever, D., Frans, E., Wilmer, A., et al. (2000). Thrombocytopenia and prognosis in intensive care. Critical care medicine, 28, 1871-1876. https://doi.org/10 $.1097 / 00003246-200006000-00031$

15. Yang, M., Ng, M. H. and Li, C. K. (2005). Thrombocytopenia in patients with the severe acute respiratory syndrome. Hematology, 10, 101-105. https://doi.org/10.1080/10245330400026170

16. Zhao, D., Yao, F., Wang, L., Zheng, L., Gao, Y., Ye, J., et al. (2020). A comparative study on the clinical features of COVID-19 pneumonia to other pneumonia. Clinical Infectious Diseases, 71(15), 456-761. https://doi.org/10.1093/cid/ciaa247 